\title{
ENFERMIDADE GASTROENTÉRICA E RESPIRATÓRIA EM BEZERROS INOCULADOS COM AMOSTRAS BRASILEIRAS DO VÍRUS DA DIARRÉIA VIRAL BOVINA TIPO 2 (BVDV-2) ${ }^{1}$
}

\author{
GASTROENTERIC AND RESPIRATORY DISEASE IN CALVES INOCULATED \\ WITH BRAZILIAN ISOLATES OF BOVINE VIRAL DIARRHEA \\ VIRUS TYPE 2 (BVDV - 2)
}

\author{
Mário Celso Sperotto Brum ${ }^{2}$ Charles Fernando Capinos Scherer ${ }^{3}$ Eduardo Furtado Flores $^{4}$ \\ Rudi Weiblen ${ }^{5}$ Claudio Severo Lombardo de Barros ${ }^{6}$ Ingeborg Maria Langohr ${ }^{6}$
}

RESUMO

Duas amostras brasileiras do vírus da Diarréia Viral Bovina tipo $2(B V D V-2)$ foram inoculadas em bezerros com o objetivo de avaliar a sua virulência e estudar a patogenia da infecção. Previamente à inoculação, os animais foram imunodeprimidos com dexametasona. Quatro bezerros com idades entre 45 e 90 dias (grupo A) foram inoculados com a amostra SV-260 ( $n=2)$ ou LV-96 $(n=2)$ e quatro bezerros com 6 a 8 meses de idade foram inoculados com a amostra SV-260 (grupo B). Após a inoculação, os bezerros do grupo A apresentaram anorexia, depressão, hipertermia, sinais de infecção respiratória e diarréia profusa, acompanhada de melena em dois animais. Os sinais respiratórios e digestivos progrediram, e os animais morreram ou foram sacrificados in extremis entre os dias 7 e 12 pós-inoculação. Úlceras e erosões no trato digestivo (língua, $n=4$; esôfago, $n=1$; rúmen, $n=1$ e abomaso, $n=3$ ), edema pulmonar $(n=4)$ e na mucosa do abomaso $(n=3)$; equimoses e sufusões na serosa do baço $(n=2)$, no rúmen, no intestino delgado e no ceco $(n=1)$, no coração $(n=1)$ e na mucosa da bexiga $(n=1)$ $e$ intussuscepção intestinal $(n=1)$ foram os achados macroscópicos mais marcantes. Ulceras e erosões, acompanhadas de infiltrado mononuclear na mucosa $e$ submucosa do trato digestivo e depleção linfóide nos linfonodos e placas de Peyer, foram as alterações microscópicas mais freqüentes. $O$ vírus foi detectado em vários tecidos e órgãos.

\begin{abstract}
Antígenos virais foram demonstrados por imuno-histoquímica, principalmente em células epiteliais do trato digestivo; em células mononucleares nos espaços perivasculares e peribronquiais; na cápsula e septos de linfonodos; e em linfócitos e células mononucleares das placas de Peyer e baço. Os animais do grupo $B$ apresentaram depressão, hipertermia, sinais moderados de infecção respiratória e digestiva, ulcerações na língua e bochecha, mas recuperaram-se após alguns dias. Esses resultados demonstram que as amostras de BVDV-2 foram capazes de reproduzir a enfermidade aguda quando inoculadas em bezerros e que as conseqüencias clínico-patológicas da infecção foram mais severas nos animais mais jovens.
\end{abstract}

Palavras-chave: vírus da Diarréia Viral Bovina tipo 2, BVDV-2, infecção experimental.

\section{SUMMARY}

Two Brazilian isolates of bovine viral diarrhea virus type $2(B V D V-2)$ were inoculated in calves to evaluate their virulence and to study the pathogenesis of the infection. Previously to virus inoculation, the calves were immunossupressed with dexamethasone. Four 45 to 90-days-old calves (group A) were inoculated with isolate $S V-260(n=2)$ or LV-96 ( $n=2)$, and four 6 to 8-months-old calves (group B) were inoculated with isolate SV-260. Following virus inoculation,

\footnotetext{
${ }^{1}$ Trabalho realizado com suporte financeiro do MCT, CNPq, CAPES e FINEP (Pronex em Virologia Veterinária, 215/96).

${ }^{2}$ Médico Veterinário, Acadêmico do Programa de Pós-graduação em Medicina Veterinária, Departamento de Medicina Veterinária e Preventiva (DMVP), Centro de Ciências Rurais (CCR), Universidade Federal de Santa Maria (UFSM).

${ }^{3}$ Médico Veterinário, MSc., Professor substituto no Departamento de Microbiologia e Parasitologia (DMP), Centro de Ciências da Saúde (CCS), UFSM.

${ }^{4}$ Médico Veterinário, MSc., PhD., Professor Adjunto do DMVP, CCR e do DMP, UFSM. Bolsista do CNPq (520758/96-0). DMVP/CCR/UFSM, 97105-900, Santa Maria, RS. Fone/fax: 55-220-8034. E mail: flores@ @cr.ufsm.br. Autor para correspondência. ${ }^{5}$ Médico Veterinário, MSc., PhD., Professor Titular do DMVP, e do DMP, UFSM. Bolsista do CNPq (520161/97-1).

${ }^{6}$ Médico Veterinário, Setor de Patologia Veterinária, Departamento de Patologia, CCS, UFSM.
} 
group A calves showed anorexia, depression, hyperthermia, signs of respiratory infection and profuse diarrhea, bloody in two cases. The respiratory and digestive signs progressed and the animals died or were euthanized in extremis between days 7 and 12 post-inoculation. Ulcers and erosions in the digestive tract (tongue, $n=4$; esophagus, $n=1$; rumen, $n=1$ and abomasum, $n=3)$, edema of the lung $(n=4)$ and abomasal mucosa $(n=3)$; echimosis and suffusions in the spleen serosa $(n=2)$, rumen, small intestine and ceccum $(n=1)$, heart $(n=1)$ and urinary bladder mucosa $(n=1)$ and intestinal intussuseption $(n=1)$ were the most prominent findings. Ulcerations and erosions accompanied by mononuclear cell infiltrates in the digestive tract mucosa and submucosa, and lymphoid depletion in lymph nodes and Peyer's patches were frequently observed. Infectious virus was detected in several tissues and organs. Viral antigens were detected by immunohistochemistry mainly in epithelial cells of the digestive tract, in mononuclear cells of the perivascular and peribronchial spaces; in lymph node septae and capsule; and in lymphocytes and other mononuclear cells of the spleen and Peyer's patches. Group B calves showed depression, hyperthermia, moderate signs of respiratory and digestive infection, small ulcerations in the tongue and recovered after a few days. These results demonstrate that the Brazilian BVDV-2 isolates were capable of producing an acute disease in calves upon experimental inoculation, and that the clinical and pathological consequences of the infection were more severe in young calves.

Key words: bovine viral diarrhea virus type 2, $B V D V-2$, experimental infection.

\section{INTRODUÇÃO}

O vírus da Diarréia Viral Bovina (BVDV) é um dos patógenos mais importantes de bovinos. $\mathrm{O}$ BVDV está classificado na família Flaviviridae, gênero Pestivirus, juntamente com o vírus da Peste Suína Clássica hog cholera virus) e o vírus da Doença da Fronteira (border disease virus) de ovinos (HORZINEK, 1991). Os Pestivirus são vírus pequenos (40 a 60nm de diâmetro), com envelope; possuem como genoma uma molécula de RNA de fita simples, polaridade positiva, com aproximadamente 12,5 quilobases (DONIS, 1995). De acordo com a capacidade de produzir citopatologia em cultivo celular, as amostras do BVDV podem ser classificadas em citopatogênicas (CP) e não-citopatogênicas (NCP) (GILLESPIE $\boldsymbol{e t}$ al., 1960).

Embora originalmente identificado de casos de doença gastroentérica grave (OLAFSON $\boldsymbol{e t}$ al., 1946), o BVDV tem sido mais freqüentemente associado a infecções subclínicas ou com sinais clínicos leves e passageiros. As maiores perdas estão geralmente relacionadas com a infecção de fêmeas prenhes. $\mathrm{O}$ vírus tem a capacidade de atravessar a placenta e infectar o concepto, podendo causar mortalidade embrionária ou fetal, abortos ou mumificação fetal, malformações e nascimento de terneiros fracos e inviáveis (BAKER, 1995).
No final da década de 80, uma enfermidade severa associada ao BVDV, com altos índices de morbidade e mortalidade em bovinos de todas as idades, foi descrita na América do Norte (REBBHUN et al., 1989; CARMAN et al., 1998). A análise genética e antigênica dos vírus isolados desses surtos demonstrou tratar-se de um novo genótipo de BVDV, posteriormente denominado de BVDV tipo 2 (BVDV-2 PELLERIN et al., 1994; RIDPATH et al., 1994). Os sinais clínicos observados eram aborto, doença respiratória ou entérica aguda, doença hemorrágica e trombocitopenia (CARMAN et al., 1998). Após isso, várias tentativas de reproduzir a enfermidade pelo BVDV-2 foram realizadas, nem sempre com sucesso (ELLIS et al., 1998; ODEON et al., 1999; WALZ et al., 1999; RIDPATH et al., 2000; STROFFREGEN et al., 2000). O genótipo BVDV-2 não é sinônimo de alta virulência, pois uma parcela significativa desses vírus tem sido isolada de infecções subclínicas, de animais persistentemente infectados, e como contaminantes de soro fetal bovino e vacinas (RIDPATH $\boldsymbol{e t}$ al., 1994; 2000).

No Brasil, amostras de BVDV-2 já foram isoladas de casos clínicos e de fetos saudáveis, e estudos sorológicos demonstraram que a infecção está difundida no rebanho bovino do país (FLORES et al., 2000). O presente trabalho foi realizado com o objetivo de reproduzir a enfermidade, através da inoculação de bezerros com dois isolados brasileiros de BVDV-2. Além de permitir o estudo da patogenia da infecção, a reprodução da enfermidade também pode viabilizar o uso desses isolados em testes de proteção vacinal.

\section{MATERIAL E MÉTODOS}

\section{Vírus e células}

Duas amostras brasileiras NCP do BVDV-2 (SV-260 e LV-96), isoladas de casos clínicos e caracterizadas antigênica e geneticamente (FLORES et al., 2000), foram utilizadas para a inoculação dos bezerros. As amostras foram propagadas em células de linhagem de rim bovino (MDBK- Madin Darby bovine kidney, ATCC-CCL 22), livres de pestivírus, cultivadas em meio essencial mínimo ${ }^{\mathrm{a}}$ (MEM), contendo $0,035 \mathrm{~g} / \ell$ de penicilina $^{\mathrm{b}}$ e $0,2 \mathrm{~g} / \ell$ de estreptomicina ${ }^{\mathrm{c}}$, suplementadas com $5 \%$ de soro eqüino. Os vírus foram propagados até obtenção de estoques contendo aproximadamente $10^{6,0} \mathrm{DICC}_{50} / \mathrm{m} \ell$ (doses infectantes para $50 \%$ dos cultivos celulares). A amostra Singer (BVDV-1), utilizada nos testes de soro-neutralização (SN), foi cedida pelo Dr. Ruben Donis (University of Nebraska, Lincoln, NE, EUA). 


\section{Animais e inoculação}

Nove bezerros cruzas da raça holandesa foram utilizados no experimento. Os animais foram divididos em dois grupos de acordo com a idade e inoculados separadamente. O grupo A era composto de quatro animais com idade entre 45 e 90 dias e peso médio de $60 \mathrm{~kg}$. O grupo B era constituído de quatro animais, com seis a oito meses de idade e com peso aproximado de $130 \mathrm{~kg}$. O animal utilizado como controle era da mesma idade e peso dos animais do grupo B. Previamente à inoculação, os animais foram testados para a presença de anticorpos neutralizantes contra o BVDV. Os animais do grupo A apresentaram títulos residuais de anticorpos contra a cepa Singer (entre 4 e 8 ) e os demais animais eram soronegativos. Antes da inoculação, os animais passaram por um período de adaptação de sete dias, quando foram everminados e monitorados clinicamente. Nos três dias anteriores, no dia da inoculação e um dia após, os animais receberam administração intramuscular de dexametasona ${ }^{\mathrm{d}}$ $(0,2 \mathrm{mg} / \mathrm{kg} / \mathrm{dia})$. Os animais foram inoculados com $10 \mathrm{~m} \ell$ de suspensão viral (dose total de $10^{7,0} \mathrm{DICC}_{50}$ /animal) divididos pelas vias intranasal $(5 \mathrm{~m} \ell)$ e intravenosa $(5 \mathrm{~m} \ell)$. O animal controle foi inoculado com MEM.

\section{Monitoramento clínico, virológico e sorológico \\ Os animais foram monitorados} diariamente através de exames clínicos e medição da temperatura corporal. Os animais que apresentaram quadro clínico severo foram sacrificados in extremis, submetidos à necropsia e tiveram seus tecidos coletados para a pesquisa de vírus, antígenos virais e histopatologia. A replicação do vírus foi monitorada através da pesquisa de vírus no sangue, no soro e em secreções nasais, coletados nos dias seguintes à inoculação, e em tecidos dos animais que morreram. As amostras coletadas foram submetidas à pesquisa de vírus, através da inoculação em cultivo celular, conforme descrito por BOTTON et al. (1998). As amostras de soro coletadas nos dias 0, 3, $6,9,12,14$ e 22 pós-inoculação (pi) foram testadas para a presença de anticorpos neutralizantes contra o BVDV, pela técnica de soro-neutralização (SN) (BOTTON et al., 1998).

\section{Histopatologia e imuno-histoquímica (IHC)}

Fragmentos de tecidos obtidos na necropsia foram fixados em formol tamponado a $10 \%$, incluídos em parafina e cortados a $5 \mu \mathrm{m}$ para histopatologia e imuno-histoquímica. Para os exames histopatológicos, os cortes foram corados com hematoxilina e eosina (H\&E) de acordo com protocolos de rotina. A detecção de antígenos virais nos tecidos foi realizada através da técnica de imuno-histoquímica, conforme descrito por SCHERER et al. (2001).

\section{RESULTADOS}

O histórico clínico e os achados macro e microscópicos nos animais inoculados estão apresentados na tabela 1 . Os animais apresentaram anorexia, depressão, hiperemia da mucosa nasal, secreção nasal mucosa, passando a muco-purulenta, estertores pulmonares, anemia, úlceras e erosões no sistema digestivo e diarréia. Todos os animais inoculados apresentaram uma elevação da temperatura corporal, que foi bifásica nos animais do grupo A (dias 2-3pi e nos dias anteriores à morte), e entre os dias 5 e 7 pi nos animais do grupo B. Em alguns animais, observou-se diarréia com muco e sangue, geralmente entre os dias 6 e 10pi. Pequenas lesões ulceradas na língua foram observadas em todos os animais do grupo A e em dois bezerros do grupo B, a partir do dia 7pi. Essas lesões persistiram até o dia 9pi (grupo B) e dia 12pi (grupo A). Os sinais clínicos progrediram em intensidade nos animais do grupo A, fazendo com que ficassem moribundos e em decúbito, morrendo ou sendo sacrificados in extremis. Nos animais do grupo $\mathrm{B}$, houve regressão dos sinais clínicos ao redor do dia 10pi, permanecendo somente a diarréia aquosa e a secreção nasal serosa ( $\mathrm{n}^{\circ} 100,101$ e 103), até o dia 13pi. O animal controle apresentou apenas um aumento discreto e passageiro da temperatura corporal no dia 3 após a administração da dexametasona.

O BVDV foi detectado com maior freqüência e duração nas secreções nasais e no sangue dos animais do grupo A. O vírus foi isolado de leucócitos de todos os animais inoculados, a partir do dia 1. Um animal (grupo A) eliminou o vírus até o dia 11pi. A maior freqüência de isolamento ocorreu entre os dias 3 e 7 pi, com redução progressiva a partir do dia 8 pi. Nas secreções nasais, o vírus foi detectado de maneira irregular e intermitente, a partir do dia 3 até o dia 12pi em um animal, com maior freqüência nos dias 5 e 6pi. Entre os animais do grupo A, apenas o bezerro 83 apresentou soroconversão antes da morte/sacrifício (título de 32 , no dia 12 pi). No grupo $\mathrm{B}$, todos os animais soroconverteram ao BVDV a partir do dia 9pi (títulos de 16 e 32). O animal controle não eliminou vírus e permaneceu soronegativo durante o experimento. 
Tabela 1 - Achados clínicos e patológicos em bezerros inoculados com amostras brasileiras do vírus da Diarréia Viral Bovina tipo-2 (BVDV - 2)

\begin{tabular}{|c|c|c|c|c|c|}
\hline & Animal & Amostra & Sinais clínicos & Achados de necropsia & Microscopia \\
\hline \multirow[t]{4}{*}{ GRUPO A } & 80 & SV -260 & $\begin{array}{l}\text { Apatia, hipertermia, secreção nasal, } \\
\text { úlceras e erosões na língua e } \\
\text { decúbito. Sacrificado in extremis no } \\
\text { dia } 7 \text { pi. }\end{array}$ & $\begin{array}{l}\text { Úlceras e erosões na língua e } \\
\text { esôfago, edema pulmonar. }\end{array}$ & $\begin{array}{l}\text { Úlceras e erosões na língua com infiltrado } \\
\text { mononuclear, edema da submucosa e } \\
\text { muscular do abomaso, pneumonia } \\
\text { fibrinosa aguda. }\end{array}$ \\
\hline & 83 & $S V-260$ & $\begin{array}{l}\text { Apatia, hipertermia, úlceras e erosões } \\
\text { na língua e almofada dental, } \\
\text { conjuntivite, secreção nasal muco- } \\
\text { purulenta, dispnéia, anemia e melena. } \\
\text { Decúbito, morreu no dia } 12 \text { pi. }\end{array}$ & $\begin{array}{l}\text { Úlceras e erosões na língua, } \\
\text { almofada dental e abomaso. } \\
\text { Edema pulmonar e do abomaso. } \\
\text { Equimoses e sufusões } \\
\text { subepicárdicas e subendocárdicas } \\
\text { no ventrículo esquerdo e em áreas } \\
\text { multifocais na mucosa do intestino } \\
\text { delgado. Petéquias e equimoses na } \\
\text { superfície do baço. }\end{array}$ & $\begin{array}{l}\text { Úlceras e erosões na língua e abomaso. } \\
\text { Depleção linfóide nos linfonodos e placas } \\
\text { de Peyer. }\end{array}$ \\
\hline & 81 & LV - 96 & $\begin{array}{l}\text { Apatia, hipertermia, úlceras e erosões } \\
\text { na língua, secreção nasal muco- } \\
\text { purulenta e dispnéia. Sacrificado in } \\
\text { extremis no dia } 8 \text { pi. }\end{array}$ & $\begin{array}{l}\text { Úlceras e erosões na língua, edema } \\
\text { pulmonar e do abomaso, } \\
\text { congestão na válvula íleo-cecal. }\end{array}$ & $\begin{array}{l}\text { Úlceras e erosões na língua e rúmen. } \\
\text { Edema da submucosa e muscular, úlceras } \\
\text { do abomaso com proliferação de tecido } \\
\text { fibroso. Depleção linfóide nos linfonodos } \\
\text { e placas de Peyer. }\end{array}$ \\
\hline & 82 & LV - 96 & $\begin{array}{l}\text { Apatia, hipertermia, úlceras e erosões } \\
\text { na língua, conjuntivite secreção nasal } \\
\text { muco-purulenta diarréia aquosa, } \\
\text { melena e tempo de coagulação } \\
\text { aumentado. Morreu no dia } 11 \text { pi. }\end{array}$ & $\begin{array}{l}\text { Úlceras e erosões na língua, rúmen } \\
\text { e abomaso. Edema pulmonar e do } \\
\text { abomaso. Equimoses e sufusões na } \\
\text { serosa do rúmen, baço, intestino } \\
\text { delgado e ceco. Intussucepção de } \\
\text { um segmento intestinal. Petéquias } \\
\text { na mucosa da bexiga. Área } \\
\text { hemorrágica no rim. }\end{array}$ & $\begin{array}{l}\text { Úlceras e erosões na língua, abomaso e } \\
\text { rúmen. Depleção linfóide nos linfonodos e } \\
\text { placas de Peyer. }\end{array}$ \\
\hline \multirow[t]{4}{*}{ GRUPO B } & 100 & SV -260 & $\begin{array}{l}\text { Apatia, hipertermia, secreção nasal } \\
\text { muco-purulenta, diarréia com muco e } \\
\text { melena. Recuperou-se. }\end{array}$ & - & - \\
\hline & 101 & $S V-260$ & $\begin{array}{l}\text { Apatia, hipertermia, secreção nasal } \\
\text { muco-purulenta, } \\
\text { respiratórios, lesões ulceradas na } \\
\text { língua, gengiva e bochecha. } \\
\text { Recuperou-se. }\end{array}$ & - & - \\
\hline & 102 & SV -260 & $\begin{array}{l}\text { Hipertermia, secreção nasal muco- } \\
\text { purulenta e diarréia. Recuperou-se. }\end{array}$ & - & - \\
\hline & 103 & SV -260 & $\begin{array}{l}\text { Apatia, hipertermia, secreção nasal } \\
\text { muco-purulenta, úlceras na língua e } \\
\text { diarréia. Recuperou-se. }\end{array}$ & - & - \\
\hline Controle & 104 & & Hipertermia passageira. & - & - \\
\hline
\end{tabular}

As lesões observadas na necropsia dos bezerros do grupo A (Figura 1a, 1b) estão apresentadas na tabela 1 . Os sistemas respiratório e digestivo foram os mais afetados. As lesões mais freqüentemente observadas foram úlceras e erosões na língua, edema pulmonar com áreas deprimidas e congestas, tumefação das pregas do abomaso com ulceração de suas bordas e coleção de líquido nas cavidades abdominal, torácica e pericárdica. Alterações microscópicas marcantes foram observadas nos tecidos linfóides (depleção linfóide e infiltrado inflamatório nos linfonodos retrofaríngeos, mediastínicos e mesentéricos e nas placas de Peyer) e sistema digestivo (erosões e úlceras da língua e abomaso, edema da submucosa e muscular do abomaso).

Nos animais que foram necropsiados durante a infecção aguda, o BVDV foi isolado de vários tecidos, com pequenas variações entre os animais (Tabela 2). Antígenos do BVDV foram detectados, através de IHC, principalmente em células epiteliais do trato digestivo; em células mononucleares nos espaços perivasculares e peribronquiais; na cápsula e septos de linfonodos; e em linfócitos e células mononucleares dos linfonodos, placas de Peyer e baço (Tabela 2; Figura 1c, 1d).

\section{DISCUSSÃO}

Os resultados apresentados demonstram que as amostras SV-260 e LV-96 de BVDV-2, isoladas a partir de casos de doença gastroentérica grave, foram capazes de reproduzir a enfermidade aguda quando inoculadas em bezerros imunodeprimidos artificialmente. A exemplo dos 


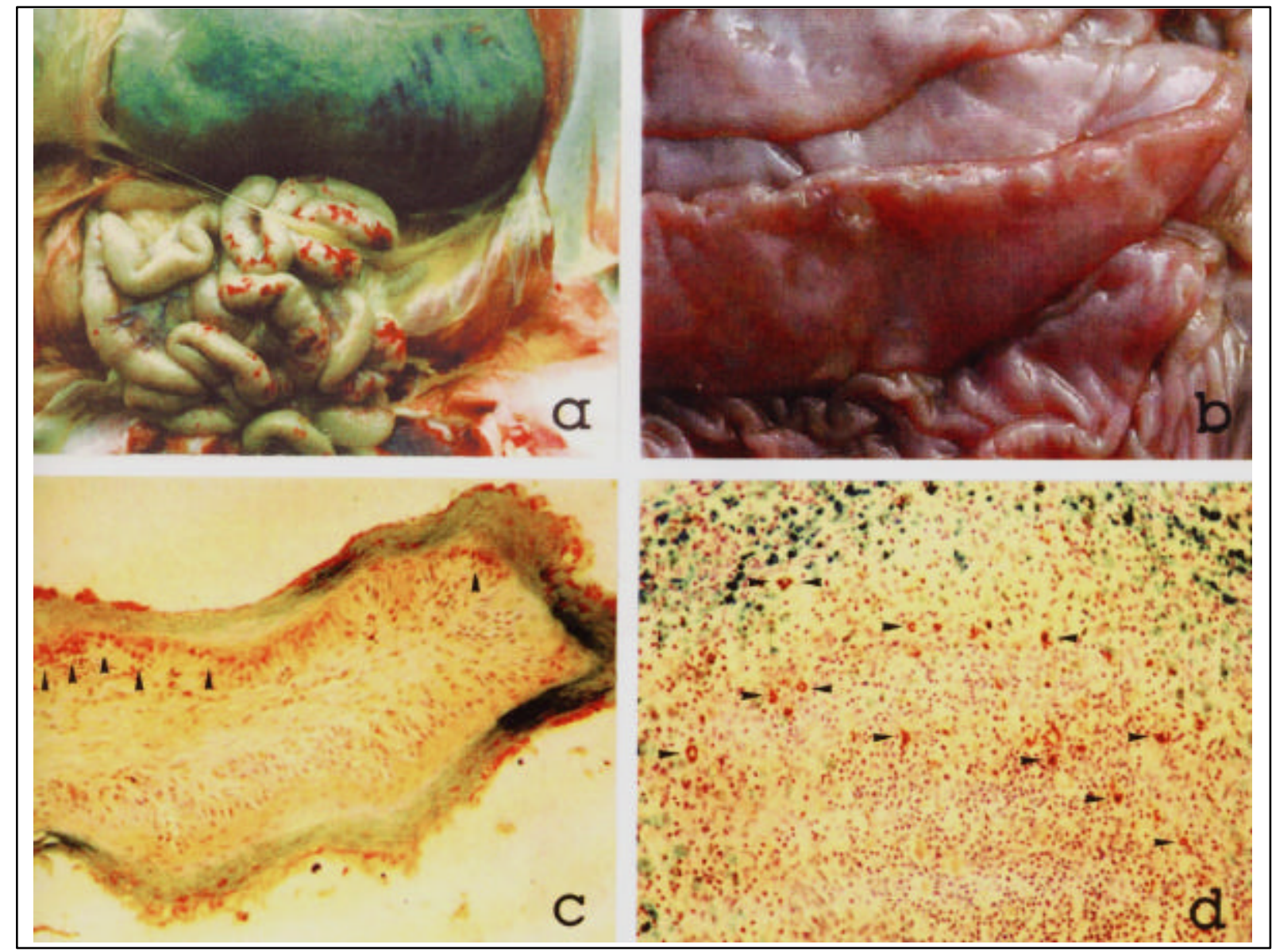

Figura 1 - Tecidos de bezerros inoculados com amostras brasileiras do vírus da Diarréia Viral Bovina-2; (a) Equimoses e sufusões na serosa do rúmen e intestino delgado do animal $n^{\circ}$ 82. (b) Edema, congestão, úlceras e erosões no abomaso do animal no 81; (c) Antígenos difusamente marcados no citoplasma de células epiteliais do rúmen (pontas de setas); (d) Células mononucleares na polpa branca do baço, positivas para antígenos virais (pontas de setas). Técnica de imuno-histoquímica utilizando o anticorpo monoclonal $15 \mathrm{c5}$ e sistema Avidina Biotina. Substrato diaminobenzidina (DAB). Coloração por hematoxilina, magnificação 250x.

casos dos quais as amostras foram isoladas, a doença gastroentérica foi acompanhada de sinais respiratórios. A enfermidade foi mais severa e até fatal nos bezerros mais jovens, enquanto os bezerros com seis a oito meses de idade apresentaram sinais clínicos de intensidade moderada e recuperaram-se. Tanto a enfermidade severa desenvolvida pelos animais jovens, como a doença de menor gravidade observada nos demais bezerros, apresentaram características clínicas e patológicas semelhantes às descritas em infecções naturais (REBBHUN et al., 1989; CARMAN et al., 1998) e experimentais (CORAPI et al., 1990; ELLIS et al., 1998; ODEON et al., 1999; WALZ et al., 1999; RIDPATH et al., 2000; STROFFREGEN et al., 2000) pelo BVDV-2. As variações mais notáveis referem-se à intensidade e duração dos sinais clínicos. No entanto, infecções agudas pelo BVDV-2 com curso clínico de intensidade muito variável e rápido, ou relativamente tardio, já foram descritas (CORAPI $\boldsymbol{e t}$ al., 1990; ELLIS et al., 1998; ODEON et al., 1999; WALZ et al., 1999; RIDPATH et al., 2000; STROFFREGEN et al., 2000).

Os sinais clínicos apresentados foram semelhantes aos observados nos casos de origem desses isolados, com algumas diferenças na duração da enfermidade e nas manifestações clínicas. A amostra LV-96 foi isolada de um caso crônico, caracterizado por episódios intermitentes de diarréia e sinais respiratórios. A amostra SV-260 foi isolada de um caso de doença gastroentérica aguda, sugestivo de Doença das Mucosas (FLORES et al., 2000). No presente estudo, os animais inoculados com as duas amostras apresentaram um quadro clínico-patológico semelhante (grupo A). A infecção teve curso com apatia severa, lesões orais, diarréia e sinais de doença respiratória. As lesões ulcerativas eram em menor número e gravidade do que nos

Ciência Rural, v. 32, n. 5, 2002. 
Tabela 2 - Distribuição de vírus e antígenos virais em tecidos de bezerros inoculados com amostras brasileiras do vírus da Diarréia Viral Bovina tipo - 2 (BVDV - 2).

\begin{tabular}{|c|c|c|c|c|c|}
\hline \multirow{2}{*}{ Órgão/tecido } & \multicolumn{4}{|c|}{ VÍRUS } & \multirow[t]{2}{*}{ ANTÍGENOS VIRAIS } \\
\hline & 80 & 81 & 82 & 83 & \\
\hline Língua & $t^{\mathrm{a}}$ & + & + & + & Células epiteliais em áreas focais da mucosa, células mononucleares no espaço perivascular \\
\hline Tonsila & + & + & + & + & Células mononucleares \\
\hline Pulmão & + & + & + & $-{ }^{b}$ & Células mononucleares nos septos alveolares; espaços perivascular e peribronquial. \\
\hline Linfonodos retrofaríngeos & + & + & + & + & Células mononucleares nos folículos linfóides, na cápsula e nos septos. \\
\hline Linfonodos mediastínicos & - & + & + & + & Células mononucleares nos folículos linfóides, na cápsula e nos septos. \\
\hline Linfonodos mesentéricos & + & + & + & - & Células mononucleares nos folículos linfóides, na cápsula e nos septos. \\
\hline Rúmen & - & - & + & - & Células epiteliais em áreas focais da mucosa, células mononucleares no espaço perivascular \\
\hline Intestino delgado & - & + & + & + & Células epiteliais em áreas focais da mucosa, células mononucleares no espaço perivascular \\
\hline Intestino grosso & - & + & + & + & Células epiteliais em áreas focais da mucosa, células mononucleares no espaço perivascular \\
\hline Placas de Peyer & - & + & + & + & Linfócitos e células mononucleares \\
\hline Baço & + & + & + & - & Linfócitos e células mononucleares na polpa branca e vermelha \\
\hline Esôfago & + & + & + & + & $\mathrm{NT}^{\mathrm{c}}$ \\
\hline Abomaso & + & + & + & + & NT \\
\hline Ceco & + & + & + & + & NT \\
\hline Válvula íleo-cecal & - & + & + & - & NT \\
\hline Reto & + & + & + & + & NT \\
\hline Rins & + & - & + & - & NT \\
\hline Bexiga & NT & + & + & + & NT \\
\hline Parótida & + & + & + & + & NT \\
\hline Tireóide & + & + & + & + & NT \\
\hline Fígado & - & + & + & - & NT \\
\hline Pâncreas & NT & + & + & - & NT \\
\hline Coração & + & + & + & + & NT \\
\hline Cérebro & + & - & + & + & NT \\
\hline Cerebelo & + & - & + & + & NT \\
\hline Hipófise & - & + & + & + & NT \\
\hline Timo & + & + & + & + & NT \\
\hline Medula óssea & NT & - & + & - & NT \\
\hline
\end{tabular}

a - isolamento positivo

b - isolamento negativo

c - amostra não testada

casos naturais, localizadas na língua e no esôfago, em somente um animal ( ${ }^{\circ}$ 80). Foram observados, nos animais inoculados com a amostra SV - 260, edema, áreas ulceradas no abomaso, equimoses e sufusões na superfície capsular do baço, serosas do rúmen, intestino delgado e ceco e petéquias na mucosa da bexiga, não tendo sido descritos na infecção natural. Na descrição do caso de infecção natural pela amostra SV-260, foram observadas áreas congestas nas mucosas da língua, omaso e rúmen e úlceras extensas e profundas na língua, no palato e no esôfago (FLORES et al., 2000). As lesões microscópicas nos epitélios e tecidos linfóides foram semelhantes às descritas nos casos naturais. Depleção linfóide severa, alteração freqüentemente associada à infecção pelo BVDV (BAKER, 1995) constituem um achado marcante no presente estudo e também relatado nos casos naturais (FLORES et al., 2000). A depleção linfóide está geralmente associada à replicação do vírus nesses tecidos, como demonstrado através de isolamento viral e imunohistoquímica (Figura 1c, 1d; Tabela 2).

Um achado importante nos animais inoculados com as amostras LV-96 e SV-260 foi a presença de áreas erosivas e ulceradas no abomaso.
Esse não é um achado constante em infecções pelo BVDV, porém já foi descrito anteriormente (CARMAN et al., 1998; WALZ et al., 1999). Os demais achados macroscópicos observados no presente estudo são freqüentes em casos de infecção natural pelo BVDV, tanto na Doença das Mucosas, como na BVD aguda/hemorrágica produzida pelo BVDV-2 (CARMAN et al., 1998).

Alguns aspectos da enfermidade observados no presente estudo diferem do que foi relatado anteriormente. CARMAN et al. (1998) descreveram os surtos de BVD aguda/hemorrágica associados com BVDV-2 e observaram maior mortalidade em animais com idade inferior a dois anos. Lesões discretas a moderadas foram observadas em animais com idade superior a seis meses. Nos animais com idade inferior a seis meses, as lesões foram pouco frequientes, além de discretas e localizadas principalmente no trato digestivo superior. No presente estudo, os animais mais jovens (45 a 90 dias) foram os que desenvolveram um quadro clínico mais severo e morreram rapidamente, enquanto os animais com idade superior a seis meses desenvolveram sinais digestivos e respiratórios moderados, lesões orais discretas e recuperaram-se 
clinicamente. Outros estudos também têm relatado doença aguda severa em animais mais jovens (CORAPI et al., 1990; ELLIS et al., 1998; ODEON et al., 1999; RIDPATH et al., 2000; STROFFREGEN et al., 2000). Além dos sinais digestivos, todos os animais apresentaram sinais de infecção respiratória, que também é um achado freqüente em infecções naturais e experimentais pelo BVDV-2 (PELLERIN $\boldsymbol{e}$ t al., 1994; CARMAN et al., 1998; ODEON et al., 1999).

Assim como em casos de infecção natural (REBBHUN et al., 1989; CARMAN et al., 1998) e experimental (CORAPI et al., 1990) com BVDV-2, sinais hemorrágicos não são achados constantes sendo observados apenas ocasionalmente. Nas descrições originais da BVD aguda, a ocorrência de doença hemorrágica foi relatada em aproximadamente $15 \%$ dos rebanhos (CARMAN et al., 1998). Em contraste, trombocitopenia é um achado consistente em infecções experimentais pelo BVDV-2 (CORAPI et al., 1990; WALZ et al., 1999). No presente estudo, o animal número 82 (LV-96), além de diarréia com sangue, apresentou dificuldade de coagulação sangüínea no momento da vasopunctura (dia 10pi). Foram observadas, por ocasião da necropsia, grandes áreas hemorrágicas nas serosas do sistema digestivo e intussuscepção de um segmento do intestino delgado. Curiosamente, nos casos de infecção natural, foi a amostra SV-260 que estava associada a sinais hemorrágicos (FLORES et al., 2000). A patogenia dos eventos hemorrágicos associados à infecção pelo BVDV-2 ainda não está esclarecida. A associação de dois ou mais mecanismos produzindo dificuldade na coagulação tem sido sugerida, porém a replicação viral na medula óssea, aparentemente, produz alterações na quantidade e qualidade das plaquetas, o que poderia favorecer a ocorrência de distúrbios na coagulação sangüínea (WALZ et al., 1999). Enterites e placas de Peyer aumentadas, muitas vezes, são uma consequiência de infecções virais, podendo servir de ponto de aderência do segmento intestinal, favorecendo a ocorrência de intussuscepção (BARKER et al., 1993).

Vários estudos envolvendo inoculação experimental têm sido realizados com o objetivo de estudar a patogenia da infecção pelo BVDV-2 (CORAPI et al., 1990; ELLIS et al., 1998; ODEON et al., 1999; WALZ et al., 1999; RIDPATH et al., 2000; STROFFREGEN et al., 2000). Esse interesse foi despertado a partir dos casos originais, nos quais a severidade e os aspectos clínico-patológicos diferiam, significativamente, do que era historicamente descrito para o BVDV. Por isso, inicialmente, acreditava-se que amostras de BVDV-2 eram invariavelmente virulentas. Estudos experimentais e observações epidemiológicas posteriores, porém, demonstraram que existem amostras de BVDV-2 pouco virulentas ou mesmo avirulentas. Estas, provavelmente, constituem-se na maioria das amostras de campo (RIDPATH et al., 1994; 2000). Portanto, o genótipo BVDV-2 não deve ser considerado sinônimo de alta virulência. Os resultados do presente estudo indicam que, além das características virais, fatores como a idade dos animais parecem ser importantes determinantes das consequiências clínico-patológicas da infecção. A intensidade e a gravidade das lesões também parecem ser influenciadas pela duração do curso clínico. Em casos de infecção natural ou experimental, os animais acometidos por enfermidade aguda de curso rápido freqüentemente não desenvolvem lesões severas (CARMAN $\boldsymbol{e t}$ al., 1998; ELLIS et al., 1998; ODEON et al., 1999; RIDPATH et al., 2000).

A detecção do vírus em praticamente todos os tecidos examinados (Tabela 2) demonstra a ampla disseminação do agente no organismo dos animais inoculados. Embora as consequiências clínico-patológicas da infecção concentrem-se principalmente no rato digestivo e respiratório, o vírus dissemina-se por vários tecidos e órgãos (BAKER, 1995; ODEON et al., 1999). Em geral, as lesões digestivas e respiratórias estão associadas a infecção dos epitélios, como demonstrado pela detecção de antígenos nesses locais (Tabela 2). No entanto, apesar do quadro de infecção respiratória, os antígenos virais no pulmão restringiram-se às células mononucleares nos septos alveolares e não no epitélio pulmonar como observado anteriormente (ODEON et al., 1999).

Os achados clínico-patológicos em casos de BVD aguda são geralmente indistinguíveis de casos de Doença das Mucosas (CARMAN et al., 1998). Essas enfermidades, no entanto, podem ser distinguidas com base na sua epidemiologia e etiopatogenia. A Doença das Mucosas é uma enfermidade rara, que ocorre em animais persistentemente infectados e está associada a uma co-infecção com amostras de BVDV CP e NCP (BAKER, 1995). A BVD aguda resulta de infecção primária aguda com amostras NCP e ocorre freqüentemente em forma de surtos, nos quais vários animais são afetados (CARMAN et al., 1998).

Em resumo, os resultados obtidos demonstram que as duas amostras de BVDV - 2 são capazes de produzir manifestações clínicas severas, sobretudo em bezerros jovens. A patogenicidade e a virulência dessas amostras também possibilitam a sua utilização como vírus de desafio em testes de proteção vacinal. 


\section{FONTES DE AQUISIÇÃO}

${ }^{a}$ MEM - Eagle's Minimal Essencial Medium Gibco - Gibco, Gran Island, NY, EUA.

${ }^{\mathrm{b}}$ Penicillin-G Potassium Salt - Sigma, St. Louis, New Jersey, EUA.

${ }^{c}$ Estreptomicina - Inlab, Brasil.

dAzium Solução - Schering-Plough Veterinária, Rio de Janeiro, RJ, BR.

\section{REFERÊNCIAS BIBLIOGRÁFICAS}

BAKER, J.C. The clinical manifestations of bovine viral diarrhea infection. Vet Clin North Am, v.11, n.3, p.425-446, 1995.

BARKER, I.K., VAN DREUMEL, A.A., PALMER, N. he alimentary system. In: JUBB, K.V.F., KENNEDY, P.C.; PALMER, N. Pathology of domestic animals. 4.ed. San Diego : Academic, 1993. V.2, Cap.1. p.1-318.

BOTTON, S.A., SILVA, A.M., BRUM, M.C.S., et al. Antigenic characterization of Brazilian bovine viral diarrhea virus isolates by monoclonal antibodies and cross-neutralization. Braz J Med Biol Res, v.31, n.11, p.1429-1438, 1998.

CARMAN, S., VAN DRUMEL, T., RIDPATH, J.F., $\boldsymbol{e}$ t al. Severe acute bovine viral diarrhea in Ontario, 1993-1995. J Vet Diagn Invest, v.10, p.27-38, 1998.

CORAPI, W.V., ELLIOTT, D., FRENCH, T.W., et al. Thrombocytopenia and hemorrhages in veal calves infected with bovine viral diarrhea virus. J Am Vet Med Assoc, v.196, n.4, p.590-596, 1990 .

DONIS, R.O. Molecular biology of bovine viral diarrhea virus and its interactions with the host. Vet Clin North Am, v.11, n.3, p.393-423, 1995.

ELLIS, J.A., WEST, K.H., CORTESE, V.S., et al. Lesions and distribution of viral antigen following an experimental infection of young seronegative calves with virulent bovine virus diarrhea virus-type II. Can J Vet Res, v.62, p.161169,1998

FLORES, E.F., GIL, L.H.V., BOTTON, S.A., et al. Clinical, pathological and antigenic aspects of bovine viral diarrhea virus (BVDV) type 2 isolates identified in Brazil. Vet Microbiol, v.77, p.175-183, 2000.
GILlESPIE, J.H., BAKER, J.A., McENTEE, K.A. A cytopathogenic strain of virus diarrhea virus. Cornell Vet, v.50, p.73-79, 1960.

HORZINEK, M.C. Pestivirus-taxonomic perspectives. Arch Virol, suppl.3, p.1-5, 1991.

ODEON, A.C., KELLING, C.L., MARSHALL, D.J., et al. Experimental infection of calves with bovine viral diarrhea virus genotype II (NY - 93). J Vet Diagn Invest, v.11, p.221-228, 1999.

OLAFSON, P., MacCALLUM, A.D., FOX, F.H. An apparently new transmissible disease of cattle. Cornell Vet, v.36, p.205213, 1946.

PELLERIN, C., HURK, J.V.D., LECOMTE, J., $\boldsymbol{e}$ t al. Identification of a new group of bovine viral diarrhea virus strains associated with severe outbreaks and high mortalities. Virology, v.203, p.260-268, 1994.

REBBHUN, W.C., FRENCH, T.W. PERDRIZET, J.A., $\boldsymbol{e}$ t al. Thrombocytopenia associated with acute bovine virus diarrhea infection in cattle. J Vet Int Med, v.3, n.1, p.42-46, 1989.

RIDPATH, J.F., BOLIN, S., DUBOVI, E.J. Segregation of bovine viral diarrhea virus into genotypes. Virology, v.206, p.66-74, 1994.

RIDPATH, J.F., NEIL, J.D., FREY, M., et al. Phylogenetic, antigenic and clinical characterization of type 2 BVDV from North America. Vet Microbiol, v.77, p.145-155, 2000.

SCHERER, C.F.C, FLORES, E.F., WEIBLEN, R., $\boldsymbol{e}$ t al. Experimental infection of pregnant ewes with bovine viral diarrhea virus type 2 (BVDV 2): effects on the pregnancy and fetus. Vet Microbiol, v.79, p.285-299, 2001

STROFFREGEN, B., BOLIN, S.R., RIDPATH, J.F., et al. Morphologic lesions in type 2 BVDV infections experimentally induced by strain BVDV2-1373 recovered from a field case. Vet Microbiol, v.77, p.157-162, 2000.

WALZ, P.H., BELL, T.G., STEFICEK, B.A., et al. Experimental model of type II bovine viral diarrhea virus-induced thrombocytopenia in neonatal calves. J Vet Diagn Invet, v.11, p.505-514, 1999. 